\title{
MATERNAL AND INFANT MORTALITY EXPERT HOPEFUL FOR SA
}

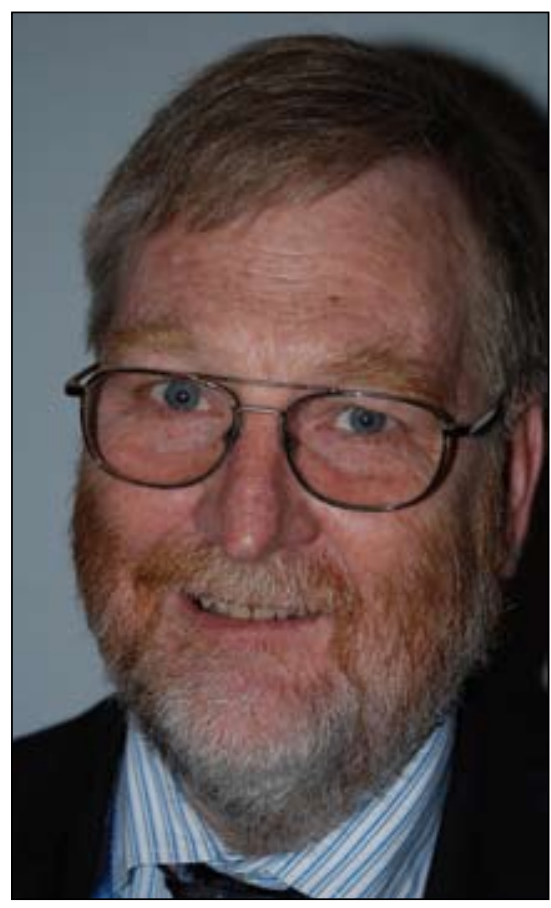

Professor Bob Pattinson, Director of the Medical Research Council's (MRC's) Maternal and Infant Health Care Strategies Research Unit and a key government advisor. Picture: Chris Bateman

Belatedly but with unprecedented determination, South Africa is slowly preparing to fill the gaping holes in its health system that contribute directly to between a quarter and half of all avoidable maternal, neonatal and child deaths.

That is the opinion of Professor Bob Pattinson, Director of the Medical Research Council's (MRC's) Maternal and Infant Health Care Strategies Research Unit and a key government advisor.

Interviewed at the 19th World Congress of Gynaecology and Obstetrics held in Cape Town last October, Pattinson was asked for a local outlook given South Africa's comparatively dismal maternal and increasing infant mortality rates.

South Africa is one of only 12 countries in which mortality rates for children have consistently risen since 1990, the baseline year for the Millenium Development Goals (MDGs).
Pattinson and his research partners have produced papers showing that thousands of deaths of mothers and babies can be prevented at district hospital level - where little has changed since an audit of 34 such facilities 5 years ago.

He said South Africa could get back on track if it boosted a few carefully selected high-impact interventions upon which a new government plan was based. These included increasing the effective implementation of basic neonatal care and boosting dual therapy prevention of mother-to-child HIV transmission programmes (with appropriate feeding choices), both to $95 \%$ coverage.

\section{The key gap is}

leadership and effective implementation at every level of the health system, including national and local accountability for service provision,' the authors said.

According to a paper to which he contributed, published in a special edition on South Africa in The Lancet ${ }^{1}$ last August, the former could save 11500 infants' lives and the latter 37200 children's lives annually in 2015 compared with 2008.

The interventions would also avert many maternal deaths and stillbirths at a cost of $24 \%$ of the public sector health expenditure with an incremental cost of R1.6 billion per year.

Such progress would put South Africa 'squarely on track' to meet MDG4 (reducing by two-thirds the mortality rate among children under five and 'probably, MDG 5,' (reducing by threequarters the maternal mortality rate).

'The costs are affordable and the key gap is leadership and effective implementation at every level of the health system, including national and local accountability for service provision,' the authors said.

\section{New health dispensation encouraging}

Pattinson told Izindaba 'We've seen a lot more from government (than in the past). The health minister has accepted the three key reports on maternal, perinatal and child mortality and is in the process of getting money to implement the recommendations in 18 priority regions'.

The Maternal Directorate in the national department of health had drawn up a set of actions with measurable targets, 'worked out with all the various stakeholders in the field'. The plan was feasible, but with the skills shortages in primary health care, task-shifting would be crucial to success because universities 'simply do not have' the teaching capacity to double their output of doctors. 'It's very difficult to produce enough doctors to make a difference,' he said.

Elaborating on the deaths of mothers which directly impacted on the poor survival figures of children under five, Pattinson said AIDS accounted for 23\% of all maternal deaths while HIV was involved in about $40 \%$. 'If we want to reduce maternal deaths we have to treat women who are HIV infected. HIV per se doesn't have much of an impact on perinatal deaths... there may be more pre-term deaths and stillbirths, but it has the greatest impact on children under five.'

Four out of five of children under five who died were either HIV exposed or infected. Better intrapartum care would also save 'a lot of lives', particularly for babies over $2.5 \mathrm{~kg}$.

Pattinson and his research
partners have produced
papers showing that
thousands of deaths of
mothers and babies can
be prevented at district
hospital level - where little
has changed since an audit
of 34 such facilities 5 years
ago.


Pattinson stressed that the biggest problem lay with the quality of maternal care at district hospitals - mainly due to staffing constraints. By WHO standards, there is only $7 \%$ of the required number of doctors available in the South African primary health care system and $17 \%$ of the nurses needed.

The answer lay in the government's mid-level worker training programme which will produce a cadre of graduates in half the time it takes to train a doctor. A curriculum had been drawn up and several universities had already begun training, with the University of Pretoria leading the rescue charge.

\section{0 million births world- wide occurred outside health facilities where there was no access to skilled care.}

\section{Other African countries more resourceful}

In Mozambique, $92 \%$ of all Caesarean sections at district hospital level are carried out by mid-level workers and in Tanzania the figure is $84 \%$ while Malawi's three paediatricians are strongly supported by this worker cadre. Malawian 'clinical officers' have been filling the staffing gap since 1976, with $88 \%$ of all emergency obstetric surgery now performed by them. This is in spite of drug supply shortages and the lack or malfunctioning of equipment needed for such procedures.

Infant and maternal mortality figures in all three countries are better than South Africa's. Studies in these countries show that with the correct training these workers, some trained straight from school and others with experience in the public health sector, produce similar outcomes to doctors when providing life-saving emergency obstetric surgical care. Also, compared with doctors, their retention rates, especially in rural and district areas, are excellent.

Professor Stefan Bergstrom of the Karolinska Institute in Sweden told the congress that some mid-level providers were performing advanced emergency surgery, not all related to pregnancy, with no statistically significant

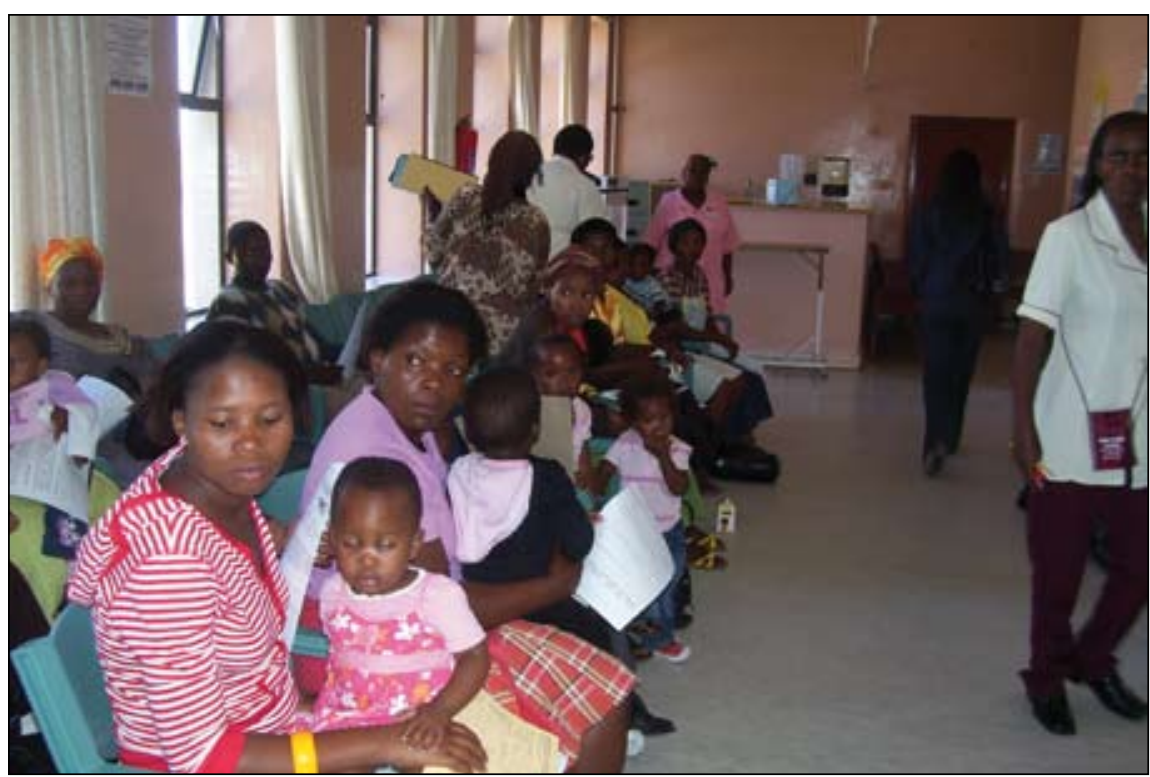

A typical scene in an understaffed rural South African hospital.

difference in outcomes when compared with medical doctors.

Many had more than a decade of work training and at least 3 years of surgical training, which is more than newly qualified doctors.

Free State Province, the site of thousands of avoidable AIDS deaths because ARV funding and supplies have not kept up with demand, ironically leads the way in task-shifting locally. Nursing sisters deal with uncomplicated $\mathrm{HIV} / \mathrm{AIDS}$ cases and dispense ARVs, referring more complicated cases to the few available doctors, producing outcomes very similar to their more highly trained colleagues.

Pattinson stressed that the biggest problem lay with the quality of maternal care at district hospitals - mainly due to staffing constraints.

Dr Gary Darmstadt of the Bill and Melinda Gates Foundation told the congress that up to 60 million births world-wide occurred outside health facilities where there was no access to skilled care. 'People don't have the tools to deal with an emergency and financial, transport and culture can be serious barriers to health care,' he added.

\section{India 'pays to treat'}

Darmstadt revealed how paying to treat patients in India led to clinics being flooded by locals, with dramatic drops in mother and child mortality. Research had also shown that community mobilisation via home-based workers resulted in a $210 \%$ increase in facility births and reduced perinatal mortality by $36 \%$.

Estimates were that communitybased workers with basic skills using a resuscitation bag and mask or simply stimulating, drying and rubbing newborns could save the lives of 7 million babies globally each year $(6$ million and 1 million lives saved per intervention, respectively). He said the health care equity gap globally meant that one in eight babies born at facilities and at home had access to neonatal resuscitation.

The Gates Foundation was identifying and prioritising for investment, the simplification and adaptation of sophisticated technology such as a R100 000 ventilator for use outside traditional health facilities.

Paying to treat patients in
India led to clinics being
flooded by locals, with
dramatic drops in mother
and child mortality.

Already at the forefront of this field is the award-winning retired University of Cape Town (UCT) newborn medicine veteran, Professor Dave Woods, who delivered a keynote 
address to the congress. Woods, his London counterpart Professor John Wyatt and fellow Capetonian, Dr Joy Lawn, of Saving Newborn Lives/Save the Children USA, teamed up with local engineers and Welsh manufacturers to produce a portable, wind-up fetal heart rate monitor 'hopefully' on the verge of mass production.

The device won an innovation award from the International Federation of Gynaecology and Obstetrics, and together with Woods' self-help intrapartum care guide books, stands to significantly reduce hypoxia-related neonatal deaths. Nearly $30 \%$ of neonatal deaths in South Africa are described to avoidable fetal hypoxia, common to under-resourced countries.

Woods, whose team has also developed a wind-up pulse oximeter which the World Health Organization 'wants to put into every operating theatre in under-resourced countries', told Izindaba this was highly appropriate technology tailored to a dire need.

Every year SA is sued for hundreds of millions by parents of children with hypoxia-related developmental disabilities that they simply couldn't otherwise afford to cope with.'

\section{Device saves 'millions' in civil claims}

'There's also a huge economic need. Every year SA is sued for hundreds of millions by parents of children with hypoxia-related developmental disabilities that they simply couldn't otherwise afford to cope with.'

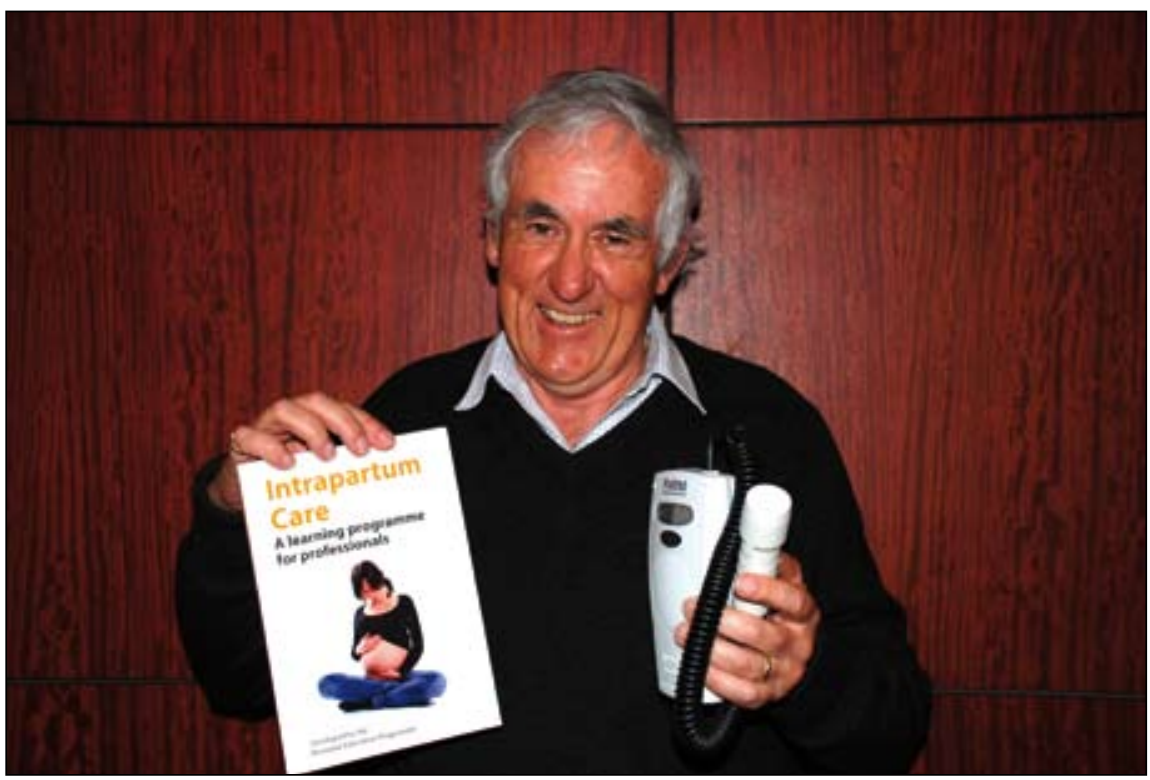

Award-winning, retired University of Cape Town newborn medicine veteran, Professor Dave Woods. Picture: Chris Bateman

The most available tool in local primary care settings at present was the Pinard fetal stethoscope (cheap and widely available), but inefficient in accurately counting the fetal heart rate. Commercially available Doppler ultrasound fetal heart rate monitors were prohibitively expensive, broke easily and relied on replaceable batteries, all unsuitable in underresourced settings.

His team's Doppler monitor was robust and inexpensive, had internal rechargeable batteries and could be run on electric mains, solar power, a car battery or the wind-up crank at the back of the device.

The device would help avert the all-too-common tragedy of 'a perfectly developed baby that dies in the last two hours of pregnancy' by detecting the onset of hypoxia, while the self-help manual guided caregivers on what to do.
A pioneer in distance learning for intrapartum care, Woods has codeveloped 13 different courses over 15 years and the device innovation is aimed at providing his 50000 current students and future ones with the tools for their new skills.

The three academic/clinicians have formed a not-for-profit section 21 company, ceding the intellectual property rights to the engineers (FreePlay Energy, makers of wind-up radios and flash lights), in return for the device development. They are hoping the international award will give them the impetus needed for the Welsh company to secure upfront securities to begin mass production.

\section{Chris Bateman}

. Chopra M, et al. Saving the lives of South Africa's mothers, babies and children: can the health system deliver? Published online in The Lancet, 25 August 2009: DOI: 10.1016/S0 1406736(09)61123-5 